\title{
Análise da cobertura vegetal de uma unidade de conservação do Pantanal de Mato Grosso do Sul, a partir da aplicação de sensoriamento remoto
}

Analysis of the vegetable coverage of a conservation unit of Pantanal of Mato Grosso do Sul state, from remote sensing application

Análisis de la cobertura vegetal de una unidad de conservación Pantanal en Mato Grosso do Sul desde la aplicación de detección remota

Recebido: 20/05/2021 | Revisado: 28/05/2021 | Aceito: 16/07/2021 | Publicado: 25/07/2021

\author{
Marcus Vinicius Freitas Bezerra \\ ORCID: https://orcid.org/0000-0002-7931-5288 \\ Universidade Federal de Mato Grosso do Sul, Brasil \\ E-mail: marcusxp@hotmail.com \\ César Cláudio Cáceres Encina \\ ORCID: https://orcid.org/0000-0001-8061-9804 \\ Universidade Federal de Mato Grosso do Sul, Brasil \\ E-mail: ccaceres.encina@gmail.com \\ Helen Rezende de Figueiredo \\ ORCID: https://orcid.org/0000-0002-6580-8305 \\ Universidade Federal de Mato Grosso do Sul, Brasil \\ E-mail: helenrezende.bio@gmail.com \\ Fabrício Bau Dalmas \\ ORCID: https://orcid.org/0000-0001-7547-6642 \\ Universidade Guarulhos, Brasil \\ E-mail: fbdalmas@gmail.com \\ Antonio Conceição Paranhos Filho \\ ORCID: https://orcid.org/0000-0002-9838-5337 \\ Universidade Federal de Mato Grosso do Sul, Brasil \\ E-mail: antonio.paranhos@pq.cnpq.br
}

\begin{abstract}
Resumo
Neste trabalho é apresentada uma abordagem geográfica ambiental diretamente associada ao uso das Geotecnologias como forma de avaliação de fitomassa. A referida análise é direcionada a uma das Unidades de Conservação localizadas no Pantanal de Mato Grosso do Sul, a Reserva Particular do Patrimônio Natural (RPPN) Fazenda Penha, criada em 1997. A partir de imagens Landsat 5 e Landsat 8, buscou-se pela análise do comportamento espaço-tempo no período de 29 (vinte nove) anos com base em imagens USGS, antes e depois da criação da RPPN. O índice espectral empregado foi o Índice de Vegetação por Diferença Normalizada (NDVI), além da composição multitemporal a partir dos resultados de cada ano, a composição multitemporal para as bandas do vermelho e a composição multitemporal para as bandas do infravermelho próximo de cada ano. A avaliação também envolveu o estudo das áreas de entorno, com a geração de buffers de 5 mil metros. as imagens mostram a perda de fitomassa na região da Serra do Amolar. O mesmo ocorreu no entorno da Unidade. Houve menor refletância da banda do infravermelho próximo e maior refletância na banda do vermelho. Sugere-se que no ano de 2016 houve menor incidência de precipitação ou maior evaporação na região, contribuindo para uma seca acentuada na Serra do Amolar e consequentemente menor valor de NDVI.
\end{abstract}

Palavras-chave: Sensoriamento remoto; Unidade de conservação; Pantanal, NDVI; Composição multitemporal.

\begin{abstract}
This work presents an environmental geographical approach directly associated with the use of Geotechnologies as a form of phytomass assessment. This analysis is directed to one of the Conservation Units located in the Pantanal of Mato Grosso do Sul, the Private Reserve of Natural Heritage (RPPN) Fazenda Penha, created in 1997. From the Landsat 5 and Landsat 8 images, the analysis was sought of space - temporal behavior in the period of 29 (twentynine) years based on images from the USGS, before and after the creation of the RPPN. The spectral index used was the Normalized Difference Vegetation Index (NDVI), in addition to the multitemporal composition from the results of each year, the multitemporal composition for the red bands and the multitemporal composition for the near infrared bands of each year. The evaluation also involved the study of the surrounding areas, with the generation of shock absorbers of 5,000 meters. the images show the loss of phytomass in the Serra do Amolar region. The same occurred in the vicinity of the Unit. There was less reflectance in the near infrared range and greater reflectance in the red
\end{abstract}


range. It is suggested that in 2016 there was a lower incidence of precipitation or greater evaporation in the region, contributing to a severe drought in the Serra do Amolar and consequently lower NDVI value.

Keywords: Remote sensing; Conservation unit; Pantanal; NDVI; Multitemporal composition.

\begin{abstract}
Resumen
Este trabajo presenta un enfoque geográfico ambiental directamente asociado con el uso de Geotecnologías como forma de evaluación de la fitomasa. Este análisis tiene como objetivo una de las Unidades de Conservación ubicadas en el Pantanal de Mato Grosso do Sul, la Reserva Privada de Patrimonio Natural de Fazenda Penha (RPPN), creada en 1997. Utilizando las imágenes Landsat 5 y Landsat 8, buscamos un análisis de el espacio - comportamiento durante un período de 29 (veintinueve) años basado en imágenes del USGS, antes y después de la creación de la RPPN. El índice espectral utilizado fue el Índice de Vegetación de Diferencia Normalizada (NDVI), además de la composición multitemporal de los resultados para cada año, la composición multitemporal para las bandas rojas y la composición multitemporal para las bandas del infrarrojo cercano de cada año. La evaluación también implicó el estudio del entorno, con la generación de amortiguadores de 5.000 metros. Las imágenes muestran la pérdida de fitomasa en la región de Serra do Amolar. Lo mismo sucedió en la Unidad. Hubo menos reflectancia en el rango del infrarrojo cercano y mayor reflectancia en el rango del rojo. Se sugiere que en 2016 hubo una menor incidencia de precipitación o mayor evaporación en la región, contribuyendo a una fuerte sequía en la Serra do Amolar y consecuentemente a un menor valor de NDVI.
\end{abstract}

Palabras clave: Detección remota; Unidad de conservación; Pantanal; NDVI; Composición multitemporal.

\title{
1. Introdução
}

A Geografia, dentre seus diversos conceitos, pode ser compreendida, de acordo com Moraes (2003), como uma ciência de síntese a qual relaciona fundamentos da natureza e da sociedade. Entre estes dois elementos ocorrem interações as quais resultam numa determinada organização social originando as feições do espaço geográfico.

Assim, o espaço geográfico vem a ser um elemento complexo, de fundamental importância para o estudo da Geografia. Conforme apresenta Tuan (1983), a percepção do espaço pelo homem depende da qualidade de seus sentidos e de sua mentalidade, da capacidade da mente extrapolar além dos dados percebidos. $\mathrm{O}$ indivíduo, por sua vez ocupa o espaço e desenvolve usos para si.

Conforme Lages (2004), a apropriação de uma porção de terra caracteriza a constituição de um território. No que lhe concerne o território, Haesbaert (1997) o define como um espaço delimitado e controlado sobre o qual se exerce um determinado poder, especialmente o de caráter estatal. Saquet (2002) descreve a territorialização como fator gerador da apropriação e da construção social. Um dos usos do território é o uso da proteção ambiental ou conservação, o qual está intrinsecamente associado ao objetivo deste trabalho.

Ratzel (2011) estabelece que o ser humano sofra influências das condições naturais, as quais determinam sua forma de ser, acarretando na necessidade de organização do espaço para a manutenção da vida dos indivíduos. A interpretação mais próxima que se tem da abordagem Ratzeliana se dá quando há necessidade de proteger o meio ambiente juntamente das características que ele possui.

Neste sentido, de acordo com Silva et al. (2005) "o Sensoriamento Remoto assumiu grande importância no monitoramento de diversos fenômenos meteorológicos e ambientais, oferecendo grande suporte na previsão do tempo e na preservação ambiental”. Segundo Paranhos Filho et al. (2008), "o Sensoriamento Remoto é a obtenção de dados ou imagens de um objeto que está distante do sensor de amostragem". As Geotecnologias são importantes formas para a análise e estudo do espaço geográfico, contudo da mensuração e avaliação do meio ambiente direcionando para discussões extremamente relevantes e necessárias ao presente e ao futuro.

Distante de se realizar uma abordagem apenas mecânica como alertada e criticada por Christofoletti (1982) e produzindo a devida conexão entre a Geografia e às Geotecnologias, este trabalho teve como objetivo a utilização de imagens dos satélites da série Landsat, apropriando-se do Sensoriamento Remoto e métodos qualitativos, para analisar eventual variação da fitomassa na Reserva Particular do Patrimônio Natural (RPPN) Fazenda Penha, entre 1987 e 2016, e constatar se a 
criação desta RPPN cumpriu com seu objetivo de conservação da diversidade biológica que ali se encontra.

\section{Materiais, Métodos e Área de Estudo}

Esta pesquisa é de natureza qualitativa, com aplicação do método de abordagem dedutivo, como também do método de procedimento sócio-analítico, conforme descrito por (Ludke e Andre, 2013 apud Pereira, 2018). A investigação qualitativa substitui a resposta pela construção, a verificação pela elaboração, bem como, a neutralidade pela participação. O investigador entra no campo com o que lhe interessa investigar, no qual não supõe o encerramento no desenho metodológico de somente aquelas informações diretamente relacionadas com o problema explícito a priori no projeto, tendo em vista que a investigação implica na emergência do novo nas ideias do pesquisador, processo esse em que o marco teórico e a realidade, no decorrer da produção teórica, entram em contradição e integração de diversas formas. Diante disso, apresenta-se a pesquisa qualitativa a partir da obtenção e análise de dados secundários, coletados diretamente com as situações estudadas, enfatizando as formas de manifestação, os procedimentos e as interações cotidianas do fato investigado, bem como, retratam a perspectiva do participante.

\section{1 Área de estudo.}

Criada no ano de 1997, através da Portaria no 7 do IBAMA, a RPPN Fazenda Penha possui 13.100 hectares e está localizada no município de Corumbá, Estado de Mato Grosso do Sul, na borda oeste do Pantanal brasileiro, na margem direita do rio Paraguai (Figura 1). Seu acesso dá-se por meio fluvial, pelo rio Cuiabá, a partir da cidade de Poconé (MT) ou pelo rio Paraguai, em Corumbá (MS), como também por meio de pista de pouso para pequenas aeronaves (BEZERRA et al., 2016).

Parte da área da RPPN está dentro da Serra do Amolar, sendo este um complexo de formações rochosas as quais se destoam da paisagem alagada do Pantanal de forma a contribuir com a preservação da Unidade de Conservação.

Figura 1. Mapa de Localização. Reserva Particular de Proteção Natural Fazenda Penha, localizada no Município de Corumbá/MS, divisa com o Estado de Mato Grosso/MT e com a Bolívia.

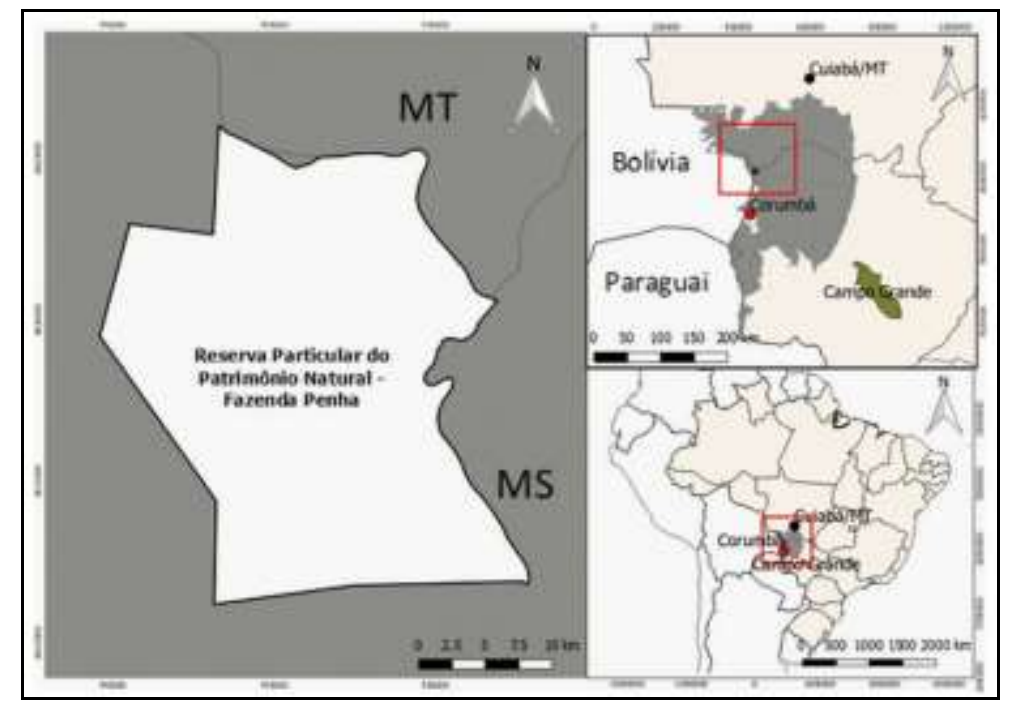

Fonte: Autores.

\subsection{Base de dados}

As informações empregadas neste trabalho compreendem a aquisição gratuita de imagens do sensor TM - Thematic Mapper (acoplado ao satélite Landsat 5) e sensor OLI - Operational Land Imager (Landsat 8), através do portal USGS (Serviço 
Geológico dos Estados Unidos), sendo uma datada do ano de 1987, sensor TM, de 01/08/1987 - uma década antes da criação da RPPN (USGS, 2017a); e uma imagem do OLI, correspondente ao ano de 2016 (USGS, 2017b). Utilizou-se também o vetor do limite oficial da RPPN Fazenda Penha (formato shapefile) obtido junto ao Sistema Informatizado de Monitoria de RPPN (SIMRPPN), do Instituto Chico Mendes de Conservação da Biodiversidade (ICMBio).

\subsection{Processamento dos dados adquiridos}

As imagens foram processadas objetivando a aplicação da equação do Índice de Vegetação por Diferença Normalizada (NDVI), de sua composição multitemporal, como também da composição multitemporal entre as bandas do vermelho e outra composição multitemporal entre as bandas do infravermelho próximo. O Índice da Vegetação por Diferença Normalizada (NDVI) é uma modelo resultante da combinação dos níveis de refletância em imagens de satélite, que provém da equação composta pelas respostas das bandas espectrais do vermelho e infravermelho (RAMOS et al., 2010). O índice espectral utilizado foi o Índice da Vegetação por Diferença Normalizada (NDVI), proposto por Rouse et al. (1973) que corresponde à Equação 1 .

$$
\text { Eq. 1. NDVI = (NIR - R) } /(\mathrm{NIR}+\mathrm{R})
$$

Onde:

NIR é a refletância da banda do infravermelho próximo;

$\mathrm{R}$ é a refletância da banda do vermelho

Para cada imagem (1987 e 2016) foi realizado o cálculo de NDVI e para cada cálculo foram considerados os resultados dos valores médios. Gamarra et al. (2016) consideram os valores médios de NDVI como "uma medida indireta da complexidade do habitat, pois indicam a complexidade estrutural (vertical) e quantidade de biomassa do habitat".

Além do cálculo de NDVI, foram geradas 3 (três) formas de composição multitemporal, sendo: composição multitemporal com os resultados de NDVI, composição multitemporal com as bandas do vermelho e composição multitemporal com as bandas do infravermelho próximo. O objetivo desta etapa foi sobrepor os resultados de cada imagem, para analisar as mudanças espectrais ocorridas nos anos de 1987 e 2016, numa só imagem, através da aplicação de uma composição falsa cor.

De acordo com o Artigo 25 da Lei 9.985 de 2000 (Brasil, 2000), a Reserva Particular do Patrimônio Natural não é obrigada a apresentar zona de amortecimento. No entanto, com o intuito de identificar potenciais agravos ambientais à RPPN Fazenda Penha foi estabelecida uma zona de amortecimento hipotética de 5000 metros, elaborada a partir do limite oficial da Unidade (buffer).

\subsection{Composição multitemporal e as correspondências de bandas para cada canal}

Para a geração de mosaicos de NDVI, Composição multitemporal entre as bandas do vermelho e composição multitemporal entre as bandas do infravermelho próximo, foram atribuídas às imagens de 1987 como banda 1 (canal vermelho) e para as imagens de 2016 banda 2 (canal do verde).

\subsection{Análise da estatística descritiva dos valores de NDVI}

Para cada imagem (1987 e 2016) foi realizado o cálculo de NDVI e para cada cálculo foram considerados os resultados dos valores médios. Gamarra et al. (2016) considera os valores médios de NDVI como "uma medida indireta da complexidade do habitat, pois indicam a complexidade estrutural (vertical) e quantidade de biomassa do habitat". 
A partir dos resultados consultados foram geradas planilhas. Para cada aplicação mencionada, foram realizados os mesmos procedimentos para a área de entorno.

\subsection{Composição falsa cor multitemporal da RPPN Fazenda Penha e da sua área de entorno}

$\mathrm{Na}$ banda do vermelho a vegetação verde, densa e uniforme absorve grandes níveis de energia do espectro eletromagnético, ficando escura. Já a banda do infravermelho próximo destaca o conteúdo de biomassa, já que a vegetação reflete muita energia (Paranhos Filho et al., 2008).

Além do cálculo de NDVI, foram geradas 3 (três) formas de composição multitemporal, sendo: composição multitemporal com os resultados de NDVI; composição multitemporal com as bandas do vermelho; e composição multitemporal com as bandas do infravermelho próximo. O objetivo foi sobrepor os resultados de cada imagem de forma a analisar as mudanças espectrais ocorridas nos anos de 1987 e 2016, numa só imagem, através da aplicação de uma composição falsa cor.

O documento oficial o qual define uma zona de amortecimento é o Plano de Manejo da Unidade de Conservação, porém em seu artigo 25, da lei do Sistema Nacional de Unidades de Conservação, uma Reserva Particular do Patrimônio Natural é excluída da obrigatoriedade em possuir zona de amortecimento. No entanto, mesmo não havendo uma zona de amortecimento oficial para a Unidade de Conservação em questão, mas para que fosse possível analisar a RPPN com um olhar mais aprofundado, macro, foi necessário explorar também seu entorno. Dessa forma, com o intuito de identificar potenciais agravos ambientais à mesma, foi estabelecida uma zona de amortecimento hipotética, de 5000 metros, gerada a partir do limite oficial da Unidade (buffer).

\subsection{Composição multitemporal e as correspondências de bandas para cada canal}

Para que fosse possível identificar a correspondência das bandas de cada ano, após seu empilhamento, foram criadas tabelas as quais identificam que a imagem do ano de 1987 corresponde a banda 1 e a imagem do ano de 2016 corresponde a banda 2, em todas as composições multitemporais (composição multitemporal com resultados de NDVI, composição multitemporal com as bandas do vermelho e composição multitemporal com as bandas do infravermelho próximo).

\section{Resultados e discussão}

\subsection{Estatística descritiva dos valores de NDVI da RPPN Fazenda Penha}

Conforme tabela abaixo o resultado do cálculo de NDVI apresenta média de 0,51 para o ano de 1987 (Tabela 1), com decréscimo do índice no ano de 2016 (0,48). Desse modo, compreende-se que houve leve redução nos níveis de fitomassa da Unidade.

Tabela 1. Valores de mínima, média, máxima e desvio padrão de NDVI, com base nos metadados do recorte da RPPN Fazenda Penha.

\begin{tabular}{ccccc}
\hline NDVI & MÍNIMA & MÉDIA & MÁXIMA & DESVIO PADRÃO \\
\hline L5 1987 & $-0,53$ & 0,51 & 0,85 & 0,32 \\
L8 2016 & $-0,8$ & 0,48 & 0,86 & 0,33 \\
\hline
\end{tabular}

Fonte: Autores. 
Levando em consideração o intervalo normalizado do NDVI $(-1$ a +1$)$ e considerando as características de fitofisionomia do Pantanal e especificamente da Unidade de Conservação em questão, este trabalho distribuiu os resultados obtidos em classes de cobertura do solo, conforme Tabela 2.

Tabela 2. Classificação de cobertura do solo com base nos intervalos de NDVI.

\begin{tabular}{ccc}
\hline \multicolumn{2}{c}{ Intervalo } & \multirow{2}{*}{ Classe de Solo } \\
mínimo & máximo & \\
\hline-1 & 0,1 & Corpos de água \\
$<0,1$ & 0,11 & Vegetação rasteira \\
$<0,11$ & 0,35 & Vegetação \\
$<0,35$ & 0,6 & arbustiva \\
$<0,6$ & 1 & Vegetação arbórea \\
$<$
\end{tabular}

Fonte: Autores.

Shimabukuro et al. (1998) já apresentava a aplicação do NDVI no Pantanal de Mato Grosso do Sul e destacava sua importância no monitoramento da dinâmica da cobertura do solo. O trabalho de Andrade et al. (2012), também aplica o NDVI como um parâmetro biofísico de superfície do Pantanal o qual permite monitorar a dinâmica da vegetação da Região. Bawa et al. (2002) relaciona o NDVI com a diversidade de espécies vegetais tropicais.

Em análise ao resultado da composição simples falsa-cor, verifica-se que a borda leste apresenta mudanças qualitativas relacionadas ao aspecto hídrico. Em 1987 havia maior concentração de corpos d'água conforme demonstrado pelas cores em tons de azul (Figura 2). Já em 2016, áreas alagadas ao leste são ocupadas por vegetação, conforme demonstrado pelas cores em tons de vermelho (Figura 3). Na borda oeste, nota-se a redução nos níveis de fitomassa a partir da atenuação dos tons de vermelho. Áreas antes ocupadas por vegetação arbustiva e vegetação arbórea deram lugar à vegetação rasteira e vegetação arbustiva.

Figura 2. Mapa de classificação da cobertura do solo da RPPN Fazenda Penha, referente ao ano 1987 (01/08/1997). Imagem Landsat - Sensor TM5.

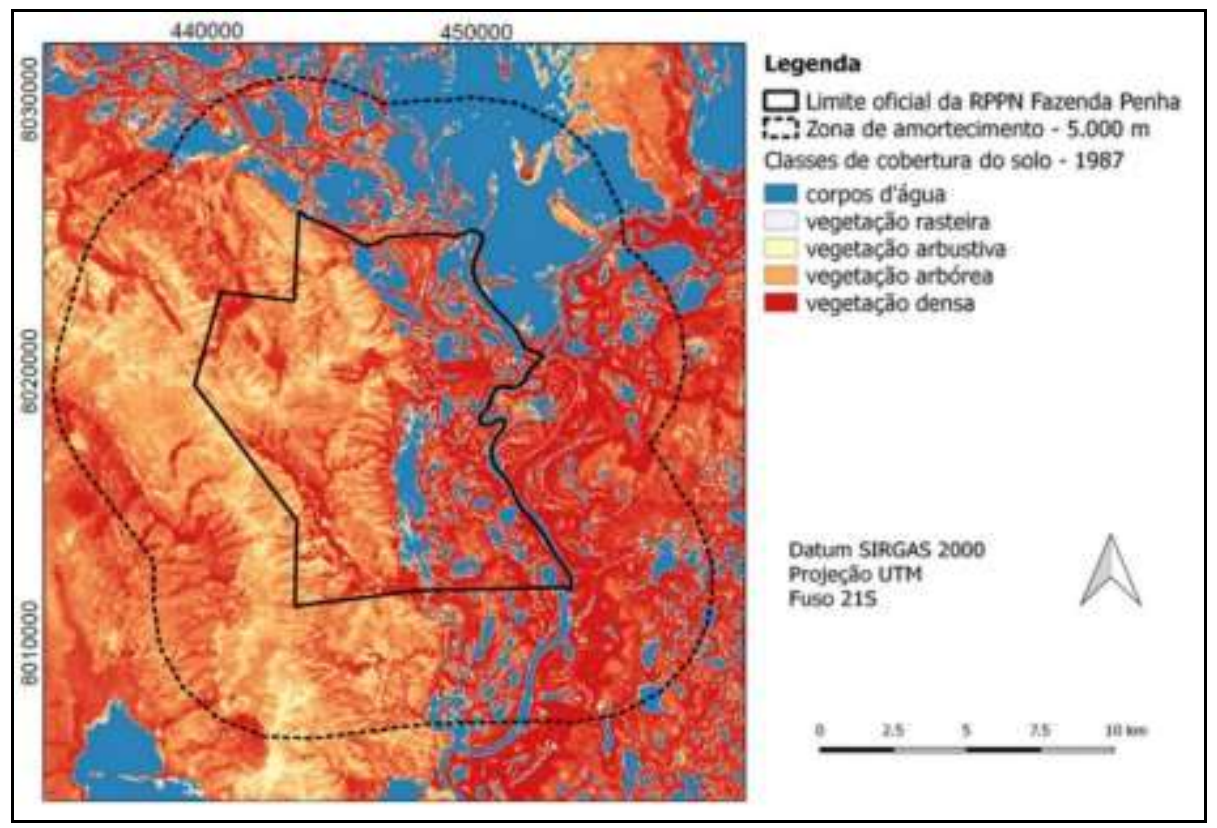

Fonte: Autores. 
Figura 3. Mapa de classificação da cobertura do solo da RPPN Fazenda Penha, referente ao ano 2016 (16/08/2016). Imagem Landsat - Sensor OLI.

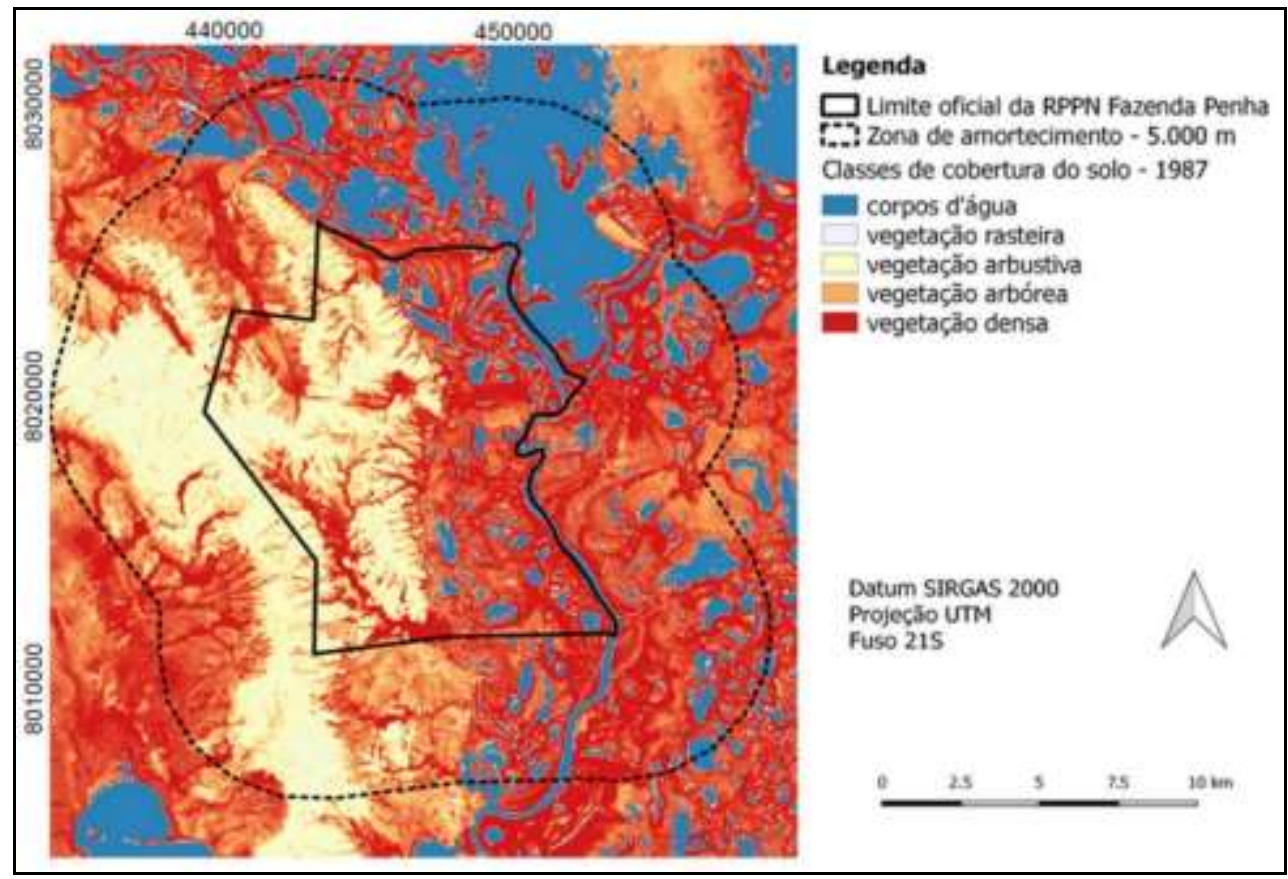

Fonte: Autores.

\subsection{Avaliação das condições vegetativas a partir das Composições Multitemporais e do Modelo Digital de Elevação}

A sequência da composição multitemporal utilizando o Vegetação por Diferença Normalizada (NDVI); banda do infravermelho próximo. Já o Modelo Digital de Elevação, elaborado com base na imagem do SRTM (Shuttle Radar Topography Mission).

\subsubsection{Composição Multitemporal do Índice de Vegetação por Diferença Normalizada RGB-NDV (1987 - 2016)}

Pode-se observar as mudanças qualitativas pontuais ocorridas do ano de 2016 comparado com 1987 (Figura 4). Os tons avermelhados correspondem à valores de NDVI de 2016 inferiores aos valores de 1987, ou seja, redução de fitomassa com base numa menor resposta espectral nesses locais. Já as áreas em verde, representam ganho de fitomassa em 2016, pois a resposta espectral nessas áreas foi maior do que a resposta em 1987. Os tons em amarelo representam pouca ou nenhuma variação de NDVI; e as áreas em preto representam corpos hídricos. Nota-se que a redução dos valores de NDVI, em 2016, acompanha uma extensa faixa de vegetação do lado oeste da Unidade de Conservação. 
Figura 4. Composição multitemporal da RPPN Fazenda Penha, utilizando NDVI.

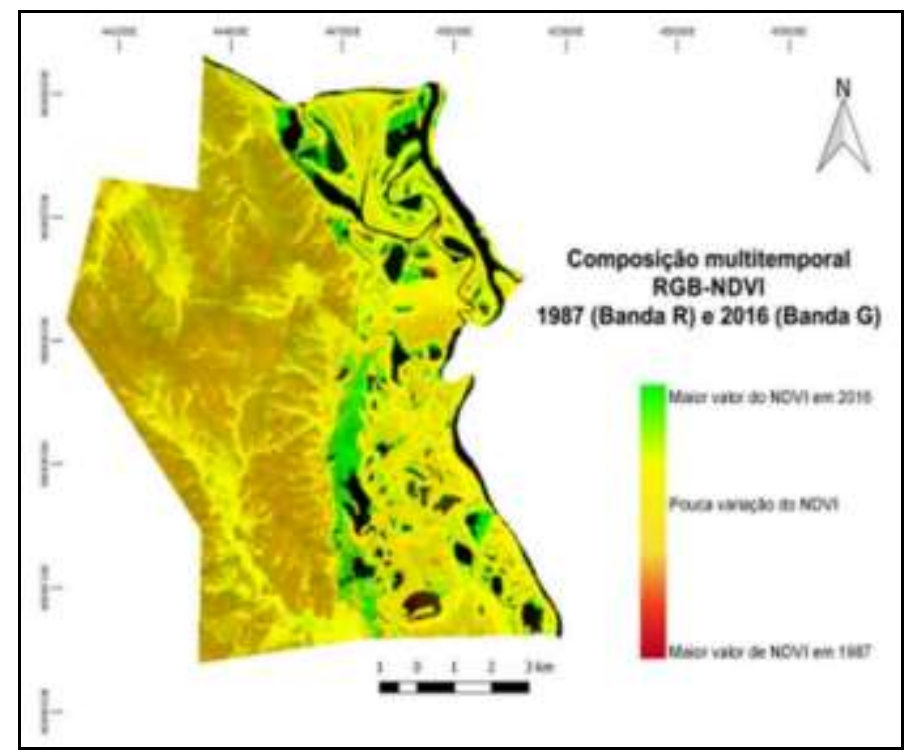

Fonte: Autores.

\subsubsection{Composição Multitemporal entre as bandas do infravermelho próximo (1987 - 2016)}

A Composição multitemporal utilizando as bandas do infravermelho próximo (1987 e 2016) apresentou maior resposta espectral em 1987 na borda oeste da UC (Figura 5). A vegetação, quando se encontra seca ou sob em estresse, absorve grandes níveis de energia do espectro eletromagnético e quando está verde, reflete. Assim, parte da imagem de 2016 apresenta menor refletância do infravermelho próximo, acarretando em áreas mais escuras. As áreas em tons de vermelho correspondem à maior valor de digital number para o ano de 1987. Já em verde, correspondem à maior valor de digital number para o ano de 2016. As áreas em amarelo representam pouca variação de digital number.

Figura 5. Composição multitemporal da RPPN Fazenda Penha, utilizando Infravermelho.

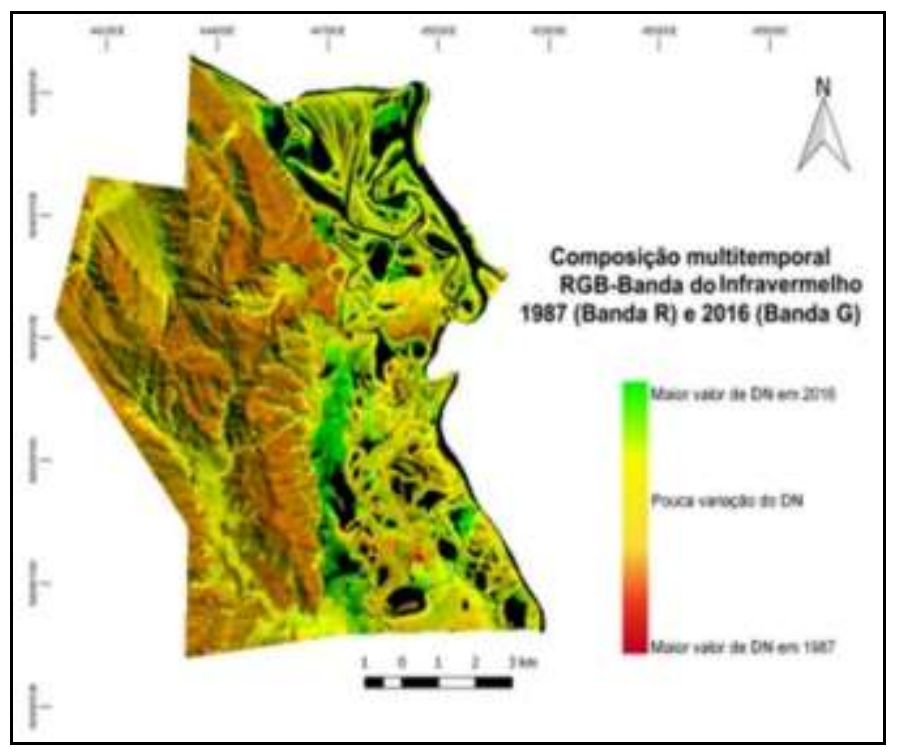

Fonte: Autores. 


\subsubsection{Composição multitemporal entre as bandas do vermelho (1987 - 2016)}

Por outro lado, a composição multitemporal entre as bandas do vermelho (1987 e 2016) mostra uma resposta espectral em tons de verde numa grande extensão da RPPN (Figura 6). A vegetação quando se apresenta verde e densa, absorve grandes níveis de energia do espectro eletromagnético, resultando em áreas mais escuras. Desta forma, as áreas em tons de vermelho correspondem à maior valor de digital number para o ano de 2016. As áreas em verde claro correspondem à maior valor de digital number para o ano de 1987. Já as áreas em tons de verde escuro representam pouca alteração de digital number.

Figura 6. Composição multitemporal da RPPN Fazenda Penha, utilizando banda vermelha.

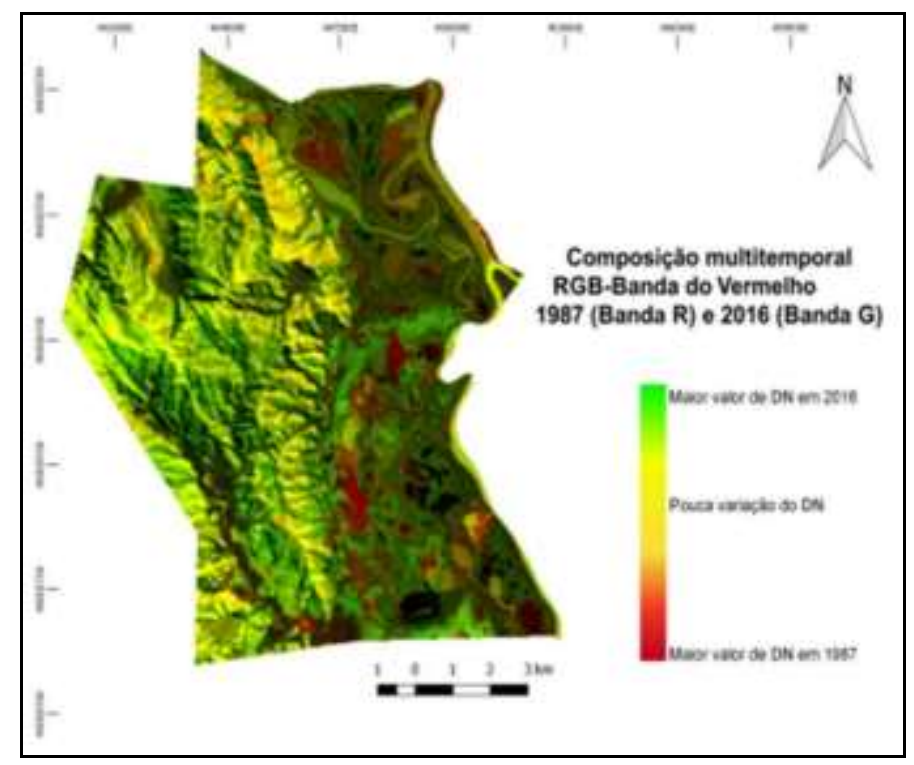

Fonte: Autores.

\subsubsection{Elaboração de um Modelo Digital de Elevação}

Levando em consideração a redução dos índices de vegetação na borda oeste da UC e, a manutenção e até mesmo sua dilatação na borda leste, verificou-se na bibliografia elementos que descrevem que a região leste sofra influência da Floresta Atlântica e a parte oeste da Floresta Chaquenha, com árvores caducifólias, que compartilha espécies do Cerrado (JARDIM et al., 2003; POTT, 2009). Diante dessas informações e com o intuito de se compreender a ecologia da paisagem da área de estudo, foi elaborado um Modelo Digital de Elevação (MDE), a partir do SRTM (Figura 7).

Em análise aos resultados apresentados bem como das características locais, verificou-se que a indicação de variação de altitude corresponde a uma parte Serra do Amolar que se encontra inserida na RPPN Fazenda Penha. A Serra do Amolar pode ser considerada uma barreira física natural, a qual divide a paisagem do lado leste e do lado oeste, e consequentemente as fitofisionomias se diferem. Conforme Ecotrópica (2016) sua altitude média é de 800 metros e chega até 1.000 metros em alguns pontos. No lado leste, encontra-se o Rio Paraguai e as baías que apresentam as formações de matas ciliares que permanecem inundadas. Assim, sugere-se que o lado oeste da RPPN apresente vegetação mais seca do que o lado leste.

Conforme apresentado, em condições ambientais desfavoráveis, as plantas reduzem a absorção do comprimento de onda do vermelho. Além disso, as formações vegetais são determinadas diretamente pela sazonalidade dos períodos de seca e cheia anuais e pela topografia. Conforme a elevação do relevo ocorrem formações de cerrado a campos de altitudes, que são ambientes mais secos. Como pode-se verificar neste MDE, as regiões mais altas apresentaram menor valor de NDVI para o ano de 2016, sugerindo que tenha ocorrido redução da unidade de conservação e/ou alta taxa de evaporação. 
A redução dos valores de NDVI na porção oeste da Unidade de Conservação pode estar associada à precipitação ou à evaporação que no Pantanal ultrapassa a precipitação durante seis a 12 meses do ano (TARIFA, 1986).

Figura 7. Modelo Digital de Elevação da RPPN Fazenda Penha.

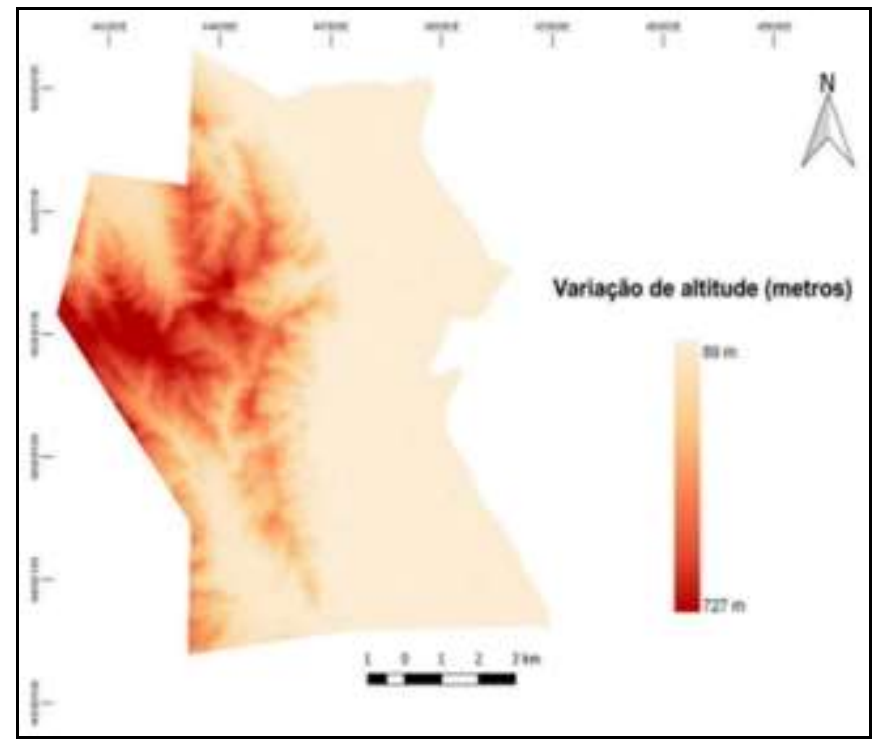

Fonte: Autores.

\subsection{Estatística descritiva dos valores de NDVI da área de entorno da RPPN Fazenda Penha}

A partir do buffer de 5.000 metros (zona de amortecimento fictícia) também foi realizado cálculo de Índice de Vegetação por Diferença Normalizada (NDVI) do entorno da RPPN. Conforme pode ser visualizado na Tabela 3, o resultado do cálculo de NDVI da área de entorno apresenta média de 0,40 para o ano de 1987, passando para 0,41 em 2016. Desse modo, compreende-se que houve leve crescimento nos níveis de fitomassa da Unidade de Conservação.

Tabela 3. Valores de mínima, média, máxima e desvio padrão de NDVI, com base nos metadados do recorte da Área de Entorno da Fazenda Penha.

\begin{tabular}{ccccc}
\hline $\begin{array}{c}\text { NDVI - ZA } \\
\text { 5.000m }\end{array}$ & MÍNIMA & MÉDIA & MÁXIMA & $\begin{array}{c}\text { DESVIO } \\
\text { PADRÃO }\end{array}$ \\
\hline L5 1987 & $-0,66$ & 0,4 & 0,87 & 0,42 \\
L8 2016 & $-0,61$ & 0,41 & 0,88 & 0,43 \\
\hline
\end{tabular}

Fonte: Autores.

\section{Conclusões}

Diante dos resultados e análises de NDVI, entende-se que este índice além de distinguir as características de fitomassa da vegetação podem também identificar a sua densidade. A partir da média de NDVI, verifica-se uma redução de 0,3 no NDVI da área da RPPN Fazenda Penha e elevação de 0,1 para sua área de entorno, direcionando a compreensão de que não existe pressão significativa na Zona de Amortecimento. As análises pontuais indicam a redução do NDVI na área que compreende a Serra do Amolar, dentro da Unidade de Conservação e em sua Zona de Amortecimento. No que abrange as composições multitemporais, tem-se menor refletância para a banda do infravermelho próximo e maior refletância na banda do vermelho, para o ano de 2016. Relacionando os resultados do NDVI com as composições multitemporais entre RED e NIR, percebe-se que houve relação significativamente positiva entre ambos. 
As áreas mais altas, no caso a Serra do Amolar, apresentaram menor valor de NDVI para o ano de 2016. No Modelo Digital de Elevação a análise constatou a variação de altitude da RPPN, a qual parte de 89 metros até 727 metros de altitude. Além das espécies caducifólias existentes, houve também a presença de incêndios na área em que predomina a Serra do Amolar (toda extensão) que contribuíram para a redução dos níveis de fitomassa. Não foi vislumbrada a hipótese de ações antrópicas que pudessem interferir nos resultados trabalhados. Primeiramente, a RPPN está distante de centros urbanos, em seguida, seu acesso se dá de forma bastante dificultosa. Destaca-se o fato da Serra do Amolar ser uma barreira natural para atividades antrópicas, visto sua dificuldade de acesso, sendo um aspecto em potencial para a continuidade da preservação da Unidade de Conservação, pois como aborda Santos (2002), o homem se apropria e modifica a paisagem/território, podendo causar alterações negativas em sua fisiografia. Porém, para avaliar de forma mais eficaz se os impactos possam ter sido causados/gerados por ações antrópicas, é necessário o aprofundamento do estudo em imagens de satélites anteriores ao ocorrido, analisando o sentido da queimada e a propriedade rural em que ocorreu.

A função de preservação da UC, apesar da leve perda de fitomassa (em função das queimadas) vem sendo cumprida, assim como a preservação da Serra do Amolar. A perda de território abordada por Ratzel (2011) é considerada a pior perda de uma sociedade, um sinal de enfraquecimento e que pode ser compreendido no caso da RPPN como possíveis erros de gestão do espaço geográfico em questão, como fiscalização, falta de ferramentas administrativas capazes de interromper esse processo, como também uma deficiência dos instrumentos de gestão ambiental.

Por fim, a relação entre o NDVI e a análise multitemporal correspondem a elementos importantes na análise da variação da cobertura vegetal, em unidade de conservação. A utilização de imagens e softwares gratuitos favorece uma análise sem custos para sua elaboração. Da mesma forma, os métodos de sensoriamento remoto contribuem para estudos direcionados à conservação de ecossistemas e otimizam o tempo de elaboração, podendo ser empregados em outras áreas do Pantanal, como também em outras Unidades de Conservação pelo país.

Desta forma este trabalho contribui para a pesquisa do espaço geográfico no âmbito das Unidades de Conservação no Pantanal, identifica e evidencia possíveis perdas de território da RPPN Fazenda Penha, diante a alteração de vegetação identificada nas imagens trabalhadas, bem como propõe a elaboração de um Plano de Manejo para a Unidade, mesmo sendo facultado esse dever aos seus proprietários.

\section{Agradecimentos}

Os autores agradecem ao PGTA/UFMS (Programa de Pós-Graduação em Tecnologias Ambientais), da Faculdade de Engenharias, Arquitetura e Urbanismo (FAENG) da Fundação Universidade Federal de Mato Grosso do Sul (UFMS).

O presente trabalho foi realizado com apoio da Coordenação de Aperfeiçoamento de Pessoal de Nível Superior Brasil (CAPES) - Código de Financiamento 001 pela bolsa de doutorado de César Claudio Cáceres Encina. Agradecemos ainda a CAPES pelo acesso ao Portal de Periódicos.

Ao CNPq (Conselho Nacional de Desenvolvimento Científico e Tecnológico) pela bolsa de produtividade em pesquisa de A. C. Paranhos Filho (CNPq Processo 305013/2018-1).

O presente trabalho foi realizado com apoio da Fundação Universidade Federal de Mato Grosso do Sul - UFMS/MEC - Brasil.

\section{Referências}

Andrade, R. G., Sediyama, G. C., Paz, A. R., Lima, E. P. \& Facco, A. G. (2012) Geotecnologias aplicadas à avaliação de parâmetros biofísicos do Pantanal. Pesquisa Agropecuária Brasileira, 47(9), 1227-1234.

Bawa, K., Rose, J., Ganeshaiah, K. N., Barve, N., Kiran, M. C. \& Umashaanker, R. (2002). Assessing biodiversity from space: an example from the Western Ghats, India Conservation Ecology, 6(2). 7. 
Bezerra, M. V. F., Alves, T. R., \& Paranhos Filho, A. C. (2016). Análise multitemporal, com base no Índice de Vegetação por Diferença Normalizada (NDVI), da cobertura vegetal da Reserva Particular de Patrimônio Natural Penha (RPPN Penha), em Corumbá/MS. Anais... Simpósio de Geotecnologias no Pantanal Geopantanal, 6, Cuiabá, 2016. Anais, 191-196.

BRASIL. Lei no 9.985 de 2000. (2021). Regulamenta o art. 225, §1º, incisos I, II, III e VII da Constituição Federal, institui o Sistema Nacional de Unidades de Conservação da Natureza e dá outras providências. < http://www2.mma.gov.br/port/conama/legiabre.cfm?codlegi=322>

Christofoletti, A. (1982). As características da nova geografia. In: Christofolettia (Org.) Perspectivas da geografia. DIFEL. 71-101.

ECOTRÓPICA. (2016). Reserva Particular do Patrimônio Natural. http:// www.ecotropica.org.br/rppns/1.

Gamarra, R. M., Teixeira-Gamarra, M. C., Carrijo, M. G. G. \& Paralhos Filho, A. C. (2016). Uso do NDVI na análise da estrutura da vegetação e efetividade da proteção de unidade de conservação no cerrado. RA 'E GA-O Espaço Geográfico em Análise, (37) 307-332.

Haesbaert, R. (1997). Território, poesia e identidade. Espaço e cultura, (3)20-32.

Jardim, A., Killeen, T. J. \& Fuentes, A. (2003). Guia de los arboles y arbustos del Bosque Seco Chiquitano, Bolívia. Santa Cruz de la Sierra: Editorial FAN. $324 \mathrm{p}$.

Lages, V. N., Braga, C. \& Morelli, G. (2004). Territórios em movimento: cultura e identidade como estratégia de inserção competitiva. SEBRAE.

Moraes, A. C. R. (2003). Geografia: pequena história crítica. Annablume.

Paranhos Filho, A. C., Lastoria, G. \& Torres, T. G. (2008). Sensoriamento remoto ambiental aplicado: introdução às geotecnologias. Ed. UFMS. 198 p.

Pereira A. S. et al. (2018). Metodologia da pesquisa científica. UFSM.

Pott, A. \& Pott, V. J. (2009). Vegetação do Pantanal: fitogeografia e dinâmica. Anais... Simpósio de Geotecnologias no Pantanal, (2), $1065-1076$.

Ramos, R. R. D., Lopes, H. L., Melo Junior, J. C. F., Candeias, A. L. B. \& Siqueira Filho J. A. (2010). Aplicação do Índice da Vegetação por Diferença Normalizada (NDVI) na Avaliação de áreas Degradadas e Potenciais para Unidades de Conservação. Anais... Simpósio Brasileiro de Ciências Geodésicas e Tecnologias da Geoinformação. 1-6.

Ratzel, F. (1983). O Solo, a Sociedade e o Estado. Revista do Departamento de Geografia / Departamento de Geografia. Faculdade de Filosofia, Letras e Ciências Humanas. Universidade de São Paulo. 2, 93-101.

Rouse, J. W., Haas, R. H., Schell, J. A. \& Deeering, D. W. (1973). Monitoring vegetation systems in the Great Plains with ERTS (Earth Resources Technology Satellite). Anais... Third Earth Resources Technology Satellite Symposium, Greenbelt, MD, NASA (National Aeronautics and Space Administration), p. 309317.

Santos, M. (2002). A natureza do espaço: técnica e tempo, razão e emoção. Edusp.

Saquet, M. A. (2003). Os tempos e os territórios da colonização italiana. EST Edições, v. 2001. 2003.

Shimabukuro, Y. E., Novo, E. M. \& Ponzoni, F. J. (1998). Índice de vegetação e modelo linear de mistura espectral no monitoramento da região do Pantanal. Pesquisa Agropecuária Brasileira, 33(13), 1729-1737.

Silva, B. B. da, Lopes, G. M. \& Azevedo, P. V. de. (2005). Determinação do albedo de áreas irrigadas com base em imagens Landsat 5 - TM. Revista Brasileira de Agrometeorologia, 13(2), 201-211.

Tarifa, J. R. (1986). O sistema climático do pantanal: da compreensão do sistema a definição de pesquisa climatológica. Anais... I Simpósio sobre Recursos Naturais Sócio-econômicos do Pantanal. Corumbá: DPT, Documento nº 5, EMBRAPA, p. 09-27.

Tuan, Yi-Fu. (1983). Espaço e lugar. Difel, p. 01-22.

United States Geological Survey - USGS. Earth Explorer. 1987. Imagens Landsat 5. Órbita 227, ponto 072. http://earthexplorer.usgs.gov/.

United States Geological Survey - USGS. Earth Explorer. 2016. Imagens Landsat 8. Órbita 227, ponto 072. http://earthexplorer.usgs.gov/. 